\title{
Cumplimiento del tercero, oposición del deudor y derecho a la liberación*
}

Eric Palacios Martínez"

\section{Notas introductivas: algunas cuestiones sobre el cumplimiento en general. Los denominados principios del cumplimiento. El interés del acreedor}

La disciplina del cumplimiento del tercero ${ }^{1}$ en nuestro Código Civil se encuentra no solo en el precepto central de la figura identificada en la fattispecie del artículo 1222 del Código Civil, sino también en aquella normativa a que se refiere el cumplimiento en general (art. 1220 y ss. del Código Civil), el mismo que en nuestro ordenamiento positivo adopta la nomenclatura de "pago", al igual que en otras legislaciones, como la italiana. ${ }^{2}$ Es por ello oportuno, para los efectos de descubrir algunos lineamientos generales del

- A Verónika con mucho afecto

-. Profesor de Derecho Civil en la Pontificia Universidad Católica del Perú y en la Universidad de Lima. Miembro de la Academia de la Magistratura.

1 Demos cuenta del origen de la terminología utilizada por toda la doctrina. La denominación tercero deriva del hecho de que, en los ejemplos utilizados por los escolásticos, que se centraban en relaciones bilaterales, las partes de una relación generada por un contrato (o un negocio) venían designadas en modo numérico: Primus y Secundus; la persona extraña a la relación generada era denominada entonces como Tertius, que en idioma castellano puede ser traducida como tercero.

2 La preponderancia de los créditos de sumas de dinero e, incluso, la utilización del término pago en lugar de cumplimiento (el que técnicamente solo es utilizable para referirse al cumplimiento de obligaciones dinerarias) han motivado que, para la construcción del modelo de obligación, se tomen como referencia las obligaciones que se caracterizan por contener una prestación que se agota en la entrega de una suma de dinero o de otras cosas, principalmente de carácter fungible. Para darnos cuenta de que esta problemática es reconducible a nuestro Código Civil, basta con observar los artículos que tratan del riesgo de la pérdida de bienes ciertos (art. 1138), de la concurrencia de acreedores (arts. 1135 y 1136) y del "pago" (art. 1220 y ss.), los mismos que, al constituir preceptos trascendentales del libro de las obligaciones, deberían resultar 
deber de cumplimiento compatibles con la regla particular del cumplimiento del tercero, y sin perjuicio de sumar al análisis la estatuición de otras figuras, tales como la subrogación (art. 1260 y ss. del Código Civil), afrontar la temática del cumplimiento en general en vista de operar una reseña, aunque fuere relativa, sobre las implicancias conceptuales entre esta forma normal de extinción de la relación obligatoria y la actividad del tercero, no extintiva, pero sí satisfactiva, del interés del acreedor como elemento funcional-dinámico de la relación obligatoria.

Tal orientación, la de analizar previamente el cumplimiento en general, se dirige a responder la interrogante acerca de si el cumplimiento del tercero puede avecinarse dogmáticamente a aquel, lo que de verificarse generaría consecuencias sobre la aplicación de alguna normativa general al cumplimiento del tercero, tales como aquella referida a la mora del acreedor (arts. 1338 y 1339 del Código Civil), la prohibición del cumplimiento parcial (art. 1221 del Código Civil) e, incluso, a la dación en pago (art. 1265 del Código Civil), las que, en lo particular, suponen situaciones en las que la actuación del tercero se ve injustificadamente obstaculizada (rechazo del acreedor), limitada o favorecida en la verificación de su objetivo satisfactivo. Sobre estas hipótesis trataremos, en el momento oportuno, al descender a la temática particular de la posible interferencia entre el derecho, reconocido en toda la doctrina, del deudor a la liberación y la legitimidad genérica establecida a favor de cualquier tercero, es decir, extraño a la relación obligatoria, que dirija su actuación a ejecutar la prestación debida. Debe desde ya destacarse que la materia de disquisición se centra, en el presente trabajo, en la relevancia de la oposición del deudor al cumplimiento del tercero. Así, cumplir una obligación, indagando sobre su materialidad fenoméni$c a$, es sinónimo de realizar exacta y totalmente la prestación debida; ${ }^{3}$ para

aplicables a todo tipo de prestaciones contenidas en una relación obligatoria, pero que se encontrarian limitadas a los casos de prestaciones que se identifican con un dar (piénsese en el art. 1135 del Código Civil).

Sin embargo, ello, a nuestro parecer, no impide individualizar un esquema más general, que comprenda todos los comportamientos debidos por el deudor a fin de satisfacer los intereses del acreedor que no necesariamente se agotan en una prestación de dar (entrega), ni en una de hacer o de no hacer (tal y como el Código Civil aborda la problemática), puesto que tales conductas podrían suponer la realización de una tipología prestacional diversa que confluya en su ejecución particular (por ejemplo: prestación de trabajo subordinado, ejecución de una obra de reparación, la prestación del consenso contractual, la transferencia de un derecho, la abstención de una actividad de concurrencia comercial, etc.). De acuerdo con el razonamiento: BRECCIA, Humberto. "Le obligación». En Giovanni ludica e Paolo Zatti (eds.). Trattato di Diritto Privato. Milán: Dott. A. Giuffrè Editore, 1991.

3 No podemos referirnos al debate sobre la categorización del cumplimiento dentro del esquema hecho, acto y negocio, por lo extenso del problema y en tanto no ofrece una 
que el cumplimiento actúe como modo de extinción, y por tanto libere al deudor, es preciso, como señala casi toda la doctrina italiana y española, que este sea exacto, es decir, que se ajuste de forma absoluta al programa prestacional pactado, puesto que, en cuanto ello ocurra, se producirá necesariamente la satisfacción del interés del acreedor. Cualquier defecto en el comportamiento del deudor, incluso atinente a las circunstancias del mismo, generará la consecuencia de que dicha situación sea calificada como un incumplimiento (en sentido lato). ${ }^{4}$ Conviene sobre ello, con el objetivo de hacer mas sintética la exposición, utilizar el esquema inicialmente propues-

solución unívoca en el ordenamiento. Sin embargo, preciso es señalar que somos partidarios de que el cumplimiento es, en la mayoría de casos, un acto en sentido estricto y, por ello, se encuadra en la subcategoría de los llamados actos debidos. Para una reseña de las principales tendencias, véase ANDREOLI, Giusseppe. Contributo alla teoria dell'adempimento. Padua: Casa Editrice Dott. Antonio Milani (CEDAM), 1937; pero, para una demostración del cumplimiento solo como acto debido, ver el interesante trabajo de NATOLI, Ugo. "Adempimento, atto dovuto, negozio giuridico». En Scritti in onore di Salvatore Pugliatti. Vol. I. T. II. Milán: Dott. A. Giuffrè Editore, 1978, p. 1532 y ss. Presentación de Rosario Nicoló. Pubblizazioni dell’lstituto di scienze giuridiche, economiche, politiche e sociali della Universitá di Messina. Allí se afirma que "la característica constante está representada por la calificación de necesidad, que cubre infaltablemente el comportamiento del deudor. En cuanto dirigido al cumplimiento, tal comportamiento es siempre debido. Ello no excluye, sin embargo, que en concreto éste pueda presentarse con la diversa estructura del comportamiento material o del acto jurídico, o, a su vez, asumir, según los casos, el ropaje de negocio jurídico, o de momento estructural de una fattispecie negocial compleja cual es el contrato (p. 1553). De interés, para incursionar en la tesis mixta del cumplimiento, y más en particular del cumplimiento del tercero, es considerar como parte de la doctrina más reciente atiende a la necesidad de preguntarse si, entre las dos soluciones contrapuestas que, sobre el plano de la relativa cualificación jurídica, tienden respectivamente a asimilar sustancialmente el cumplimiento del débito ajeno al cumplimiento del deudor cual "acto de ejecución» o bien atribuyen al mismo naturaleza negocial o por añadidura contractual, no sea mejor preferible tomar nota de la antes mencionada ambivalencia del tal cumplimiento; y proceder después a una ulterior verificación de la misma y a la consiguiente definición de la naturaleza jurídica del cumplimiento del tercero a la luz de las implicaciones que subyacen a la disciplina directamente aplicable» (Turco, Claudio. "L'adempimento del terzo". En I/ Codice Civile. Commentario fondato da Piero Schlesinger e diretto da Francesco Donato Busnelli. Milán: Dott. A. Giuffrè Editore, 2002, pp. 85-86 lart. 1180]).

4 En tal sentido, Díez-Picazo, Luis y Antonio Gullón. Sistema de Derecho Civil. 2." ed. Madrid: Tecnos, 1986, p. 236, donde se define que «por pago entendemos, en un sentido general, el acto de realización de la prestación debida en virtud de una relación obligatoria. El pago es, en primer lugar, un acto de cumplimiento del deber jurídico o deuda que pesa sobre el deudor. El pago es, en segundo lugar, la manera normal que el deudor tiene de liberarse de la obligación (solutio). El pago es, finalmente, la forma de satisfacer el interés del acreedor. Es pago toda realización de la prestación debida (entrega de suma de dinero, de cosas específicas, realización de servicios o adopción de simples omisiones). En términos generales, el pago es un comportamiento del deudor que se ajusta al programa o proyecto de prestación establecido en el acto de constitución de la relación obligatoria». 
to por Diez Picazo - el que no compartimos en todos sus extremos como se dejará entrever-, quien, partiendo de diferenciar elementalmente entre cumplimiento y extinción de la obligación, 5 subraya que, para que el cumplimiento despliegue su plena eficacia solutoria y satisfactoria, deben concurrir una serie de exigencias, que se refieren a los sujetos que lo ejecutan, al objeto y a las circunstancias de tiempo y lugar que lo supeditan. Dichas exigencias se concretan en lo siguiente:

1. Desde el punto de vista de los sujetos, la regularidad del cumplimiento presupone capacidad y legitimación en la persona que lleva a cabo el acto y en la persona que recibe las prestaciones que se ejecutan.

2. Desde el punto de vista del objeto, son requisitos de regularidad del cumplimiento la identidad y la integridad de la prestación y su adecuación con el programa.

3. Desde el punto de vista de las circunstancias, es necesario que el cumplimiento se realice en el tiempo y el lugar exactos, de acuerdo con el negocio jurídico constitutivo de la relación obligatoria o, por lo menos, adecuado para obtener la satisfacción del interés del acreedor. ${ }^{6}$

Sería más adecuado, en vista de un análisis sistemático, el recurrir, por ejemplo, a la fórmula exacto-inexacto cumplimiento. Ello hubiese representado una oportuna elección de política legislativa, no solo en el sentido de rechazar una enumeración puntual de las varias figuras de incumplimiento, pues se evidencia la connatural imposibilidad de una adecuación perfecta de cualquier estructura estática y/o esquemática a una variedad de casos concretos, sino también, y sobretodo, de adoptar, en lugar de una genérica referencia al incumplimiento tout court, una cláusula general de responsabilidad que, asumiendo como regla la "exactitud» del cumplimiento y calificando, de forma contararia, el incumplimiento en términos de inexactitud de la prestación, aparece idónea para comprender en su valoración sistemática la vasta gama tipológica en la cual puede concretarse la inactuación de la relación obligatoria. De esta forma, se abarca tanto la hipótesis límite de la inejecución de la prestación debida por el deudor (el llamado incumplimiento absoluto), como

Lo que, en términos precisos, coincide con la temática examinada, pues, como se verá, el cumplimiento de tercero, como figura particular del cumplimiento in genere, supone justamente que el tercero cumpla materialmente la prestación debida, satisfaciendo el interés del acreedor, pero que tal suceso no produzca el efecto extintivo sino solo el traslado de la posición creditoria a favor del tercero.

- Diez PICAzo, Luis. Fundamentos del Derecho civil patrimonial. Vol. II: "Las relaciones obligatorias". Madrid: Tecnos, 1993, p. 478. 
cualquier otra anomalía de dicha prestación en la que se ponga de manifiesto su deformidad respecto al modelo asumido en el contenido de la obligación (el llamado incumplimiento relativo). ${ }^{7}$

En suma, lo que se pretende es ordenar todas las hipótesis de defectuosidad de la conducta del deudor y considerarlas todas ellas, en conjunto, como incumplimientos, puesto que de cumplimiento solo puede hablarse cuando el deudor ha desarrollado perfectamente la actividad a la que se encuentra obligado, ya que, en caso distinto, dependerá del interés concreto del acreedor la eventual liberación del deudor, al margen de la apreciación que ha de efectuarse según el criterio de la buena fe, el que, llegado el momento, podría alterar la valoración final de una conducta desviada del deudor. A lo que se llega es a la afirmación de que la única forma de que el deudor se libere estrictamente por su propia actuación es ejecutando exactamente la prestación debida en los términos descritos. En los demás casos, su eventual liberación o responsabilidad tendrá que ser dirimida acudiendo a factores externos a su específico campo de actuación (por ejemplo: la imposibilidad liberatoria).

En el cumplimiento del tercero, sin embargo, y más allá del aspecto meramente estructural enunciado líneas atrás, se debe atender a que la correlación entre prestación e interés creditorio se desarrolla de acuerdo con la circunstancia en la que el tercero, más allá de la cualificación de su comportamiento en términos de verdadero y propio cumplimiento, ejecuta la prestación contenida en la relación obligatoria vinculante entre el deudor y el acreedor realizando su interés. Esta reflexión da lugar a la exigencia de reconstruir y definir, sobre el plano "funcional" antes que sobre el plano estructural acotado, la concreta incidencia desplegada por la actuación prestacional del tercero respecto al cumplimiento del deudor sobre las situaciones jurídicas subjetivas de crédito y débito en las que se articula la relación obligatoria. ${ }^{8}$ Es obvio que este enfoque no puede establecerse en torno a la

7 De acuerdo en este punto: TurCO, Claudio. Op. cit., pp. 20-21.

8 Para la propuesta de impostar y distinguir entre los planos de incidencia funcional y de conformación estructural del cumplimiento (actuación prestacional) del tercero y del cumplimiento del deudor, es oportuno remitirse a NICOLÓ, Rosario. L adempimento dell'obbligo altrui. Milán: Dott. A. Giuffrè Editore, 1936, p. 60 y ss, para quien el interés constituye la "expresión sintética de una relación entre un sujeto y un determinado bien; constituiría el elemento teleológico para cuya realización la norma atribuye a un sujeto un poder jurídico $y$, en tal óptica, representaría el «presupuesto de aquella particular forma de tutela que se ha expresado en el derecho subjetivo. Con referencia al interés como situación-relación entre el sujeto y una dada entidad idónea para satisfacer las necesidades y ser de utilidad para aquel, ver, dentro de la teoría del objeto de los derechos, MESSINETTI, Davide. "Oggetto dei diritti». En Enciclopedia del Diritto. Vol. Xxix. Milán: Dott. A. Giuffrè Editore, 1979, p. 809. 
constatación de un resultado económicamente equivalente si la prestación hubiese sido ejecutada por el deudor; por el contrario, debe apoyarse sobre consideraciones dogmáticas, es decir, de construcción científico-jurídica, y referirse directamente a la idea de interés creditorio, en tanto este se haya diferenciado, sobre todo por su mayor amplitud, de la llamada «ventaja económican."

Afinca lo señalado que sobre el plano funcional del cumplimiento del tercero, por el lado del acreedor, no puede sino que verificarse la satisfacción del acreedor $y$, por ende, venir a menos las pretensiones del acreedor contra el deudor, mientras que, por el lado del deudor, la ejecución de la prestación por parte del tercero puede conllevar la extinción de la obligación y la liberación del deudor, siempre que el tercero no venga a subrogarse en el derecho del acreedor a pretender el cumplimiento por parte del deudor. ${ }^{10}$

Por ello, es momento de aclarar, in genere, la referencia al interés del acreedor a efectos de verificar su importancia central en la calificación del cumplimiento y, reflexivamente, de la "actuación" del tercero; y es que hasta aquí se había enfocado el tema sobre el plano material, es decir, exclusivamente sobre la falta de prestación (no-prestación), cuando es necesario, como ya se dejó planteado, también dirigir la atención sobre el plano funcional, tanto en el aspecto del cumplimiento debido como en aquella situación patológica de cooperación rehusada, justificada o no, que se centra en la falta de satisfacción del interés del acreedor: este "plano" funcional, resulta claro, de ningún modo puede contradecir o estar en contradicción con el plano material-estático anteriormente abordado.

A nuestro entender, la noción de interés se dirige a identificar el nexo de tensión entre un sujeto y un bien o entidad externa, idónea para satisfacer sus necesidades. Asume, entonces, la categoría de sustrato de la situación jurídica tutelada por el derecho. ${ }^{11}$ Esta definición se ajusta al rol fundamental

9 Se ha entendido como ventaja económica la «utilidad económicamente valorable que la prestación aporta al acreedor o, más restrictivamente, el valor de mercado del bien o del servicio debido" (BIANCA, Massimo. Diritto Civile. L'obbligazione. T. 4. Milán: Dott. A. Giuffrè Editore, 1990, p. 86 y ss.).

10 De acuerdo con lo precisado por INZITARI, Bruno. "Le obbligazioni: fonti e disciplina generale». En Mario Bessone (ed.). Istituzioni di Diritto Privato. 11.a ed. Turín: G. Giappichelli Editore, 2004, p. 441.

"Es la orientación seguida por BETT1, Emilio. «Interesse (teoria generale)» En Novissimo Digesto Italiano. Vol. VIII. Turín: Unione Tipografiche Editrice Torinese (UTET), 1962, pp. 838 y ss. Desde otra óptica, diversa pero no contradictoria, el interés puede ser concebido como «la posibilidad de que una necesidad, experimentada por uno o varios sujetos determinados venga satisfecha mediante un bien" (DE CUPIS, Adriano. El daño. Teoría general de la responsabilidad civil. Traducción de la segunda edición italiana y estudio preliminar por Ángel Martínez Carrión. Barcelona: Bosch, Casa Editorial, 1970, p. 111). 
desarrollado por el interés del acreedor, subyacente a la relativa situación jurídica subjetiva identificada en el derecho de crédito, al interior del sistema de las obligaciones y del contrato. ${ }^{12}$

Es claro, en un primer momento, que el interés del acreedor coincide, o, mejor dicho, debería siempre coincidir, con la ejecución exacta de la prestación debida, por lo que necesariamente tendrá que verse satisfecho ante la ocurrencia de un comportamiento del deudor que coincida plenamente con el contenido "programático" de la relación obligatoria. De lo expuesto fluye que el interés del acreedor nunca constituye solamente un aspecto subjetivo, en el sentido de identificación con el plano de un querer interno, sino que, por el contrario, requiere o ser típicamente considerado por la correspondiente fattispecie o, en todo caso, objetivado (expresado) indubitablemente en la hipótesis concreta. En otras palabras, la coincidencia inicial con la prestación debida, dispuesta en el acto originante de la relación obligatoria, que puede corresponderse o no con la tipicidad de este respondiendo a una exteriorización expresa del propósito práctico (causalización), no podrá ser negada por el sujeto que ocupa la posición creditoria (acreedor). En caso de que la prestación sea ejecutada por el deudor en forma «exacta», según lo señalado, la equiparación entre esta situación y la satisfacción del interés del acreedor será innegable, lo que producirá la extinción de la relación obligatoria; esto, sin perjuicio de alguna situación excepcional, como, por ejemplo, se arguye en el caso, citado por la doctrina, del pago al acreedor aparente (art. 1225 del Código Givil)..$^{13}$

Cuando se presenten desviaciones en la conducta programada del deudor que involucren la alteración del principio de exactitud, entendido en forma amplia, es claro que el acreedor podrá hacer uso de su derecho de

En lo que se nos permite optar, asimilamos la primera de las concepciones, pues en ella se explica con claridad la idea de interés del acreedor dirigido a la obtención de un bien, entendido como bien o resultado.

12 Así Dı Majo, Adolfo. La esecuzione del contratto. Milán: Dott. A. Giuffrè Editore, 1967, p. 442, donde se subraya la connotación central y dinámica del interés del acreedor, que, permaneciendo en su mismo núcleo, se enriquece de los aportes y motivos nuevos que antes no se encontraban en el arco de desenvolvimiento del contrato.

13 En dicho artículo, tenemos que la solución acogida radica en la extinción de la relación obligatoria, aunque el acreedor (real) no haya sido satisfecho en su interés; se debe recalcar que, ahondando un poco, puede evidenciarse que el caso en cuestión no puede ser identificado con un supuesto de ejecución no satisfactiva como tal, sino uno que tiene como sustento la apariencia creditoria en un sujeto que ostenta la posición legitimante; así, resulta, por lo menos, discutible el acudir a él para demostrar la no necesaria equiparación entre cumplimiento exacto y satisfacción del interés, ya que el interés del acreedor (aunque aparente) estaría satisfecho en lo que concierne al deudor que ha realizado objetivamente el comportamiento destinado a tal satisfacción y, por tanto, a la extinción de la relación. 
rechazo a la prestación irregularmente ejecutada (con lo que verificaría el incumplimiento) apoyándose justamente en su falta de exactitud, con lo que eventualmente cabría la posibilidad de acudir a los mecanismos de tutela previstos por el ordenamiento ante la lesión de su interés (ejecución forzada o resolución-privación de efectos, de ser el caso). Lo mismo ocurriría con la actividad del tercero dirigida al cumplimiento, en tanto se requiere la idoneidad de dicha actividad para realizar el derecho del acreedor, el que sí, ya lo anotamos, sería realizado por la prestación del deudor. También el acreedor podría rechazar la "prestación" del tercero cuando se presenten indicios objetivos de que este no puede efectuar la atribución patrimonial con la legitimidad necesaria (por ejemplo, el tercero no es dueño de la cosa fungible entregada al acreedor); es decir, en otros términos, el acreedor podrá rechazar el ofrecimiento del tercero a cumplir cuando se aprecie que la consistencia patrimonial del tercero no asegura la inatacabilidad del pago (por ejemplo, dando lugar al peligro de una acción revocatoria).$^{14} \mathrm{En}$ tales supuestos, se puede, sin perjuicio de la equiparación entre la actividad del deudor y del tercero, marcar el rompimiento del principio acogido en un cierto momento por la doctrina tradicional. Según este, corresponde a todo tercero, en plena autonomía y libertad, el cumplir la obligación ajena, incluso contra la voluntad del acreedor; por tanto, constituye carga (onere) de este recibir el cumplimiento también del tercero. ${ }^{15}$

En lo que atañe al cumplimiento del deudor, este derecho solo se encontraría limitado por la buena fe, cuando, por ejemplo, se estima que la «inexactitud" incurrida no es de tal magnitud para permitir la resolución de la relación obligatoria, mejor dicho, del contrato. ${ }^{16}$ En lo que concierne al tercero, sin perjuicio de los casos enunciados, se denota también la posibilidad de que existan límites a su actuación dirigida al cumplimiento en los que el acreedor podría rechazarla, problemática de la que trataremos después. Otro caso de rechazo justificado, advertido no como dicber sino como

Solo en el último punto hemos seguido a NiCOLÓ, Rosario. Op. cit., p. 123.

15 Así nos lo hace saber D। MAJO, Adolfo. "Dell'adempimento in generale. Libro Quarto. Delle obbligazioni (artt. 1177 - 1200)». En Francesco Galgano (ed.). Commentario al Codice Civile Scialoja e Branca. Bolonia, Roma: Zanichelli Editore - Societá Editrice del Foro Italiano, 1994, p. 60.

16 Ello, evidentemente, si se atiende a la tesis según la cual el contrato no se extingue en el momento que produce los efectos correspondientes a su tipo y a su función; a partir de esto, se puede deducir, sin mucho esfuerzo, que la estructura del negocio, o contrato en particular, se refleja en la obligación (en este caso negocial), que más que estructura debería tener, como punto de composición de sus reglas, el contenido regulado. La idea se me ha criticado en no pocas oportunidades, y ello me incentiva a que, en el futuro, efectúe algunas disquisiciones a fin de darle mayor construcción y asidero a la afirmación efectuada. 
facultad, es la llamada oposición del deudor: punto que se abordará en la última parte de este trabajo.

De tal análisis podría, efectivamente, colegirse incluso el concepto de incumplimiento. ${ }^{17}$ Este vendría constituido como toda situación jurídica objetiva de falta de satisfacción del interés del acreedor que prescinda de cualquier valoración del comportamiento del deudor. Esto se debe a que los casos de "exactitud", si bien deben objetivamente coincidir con la satisfacción del interés, no son los únicos supuestos que pueden producirla, como sucede en el caso del "cumplimiento" del tercero, que atiende a la simple premisa según la cual, en estricto, el único que puede cumplir la prestación debida es el deudor: el tercero, en cualquier caso, podrá solamente ejecutarla ${ }^{18}$ en tanto el interés del acreedor se dirige al bien (utilidad) y la actividad del tercero realizaría el derecho-interés del acreedor sin actuar el deber de prestación que grava al deudor. ${ }^{19}$ Es claro que, en estos supuestos, prescindimos

17 El "incumplimiento" es la premisa factual de la responsabilidad contractual o por inejecución de obligaciones, como la llama nuestro Código Civil; se debe, en todo caso, recalcar brevemente que la idea de uincumplimiento" que se maneja en este punto, y en toda la problemática que nos atañe, es aquella de índole exclusivamente material. Esto conlleva exclusivamente la calificación objetiva de la realidad que se presenta ante nuestros ojos ( $y$ ello al margen de que equívocamente algunos digan que las corrientes subjetivas basan el inicio del juicio de responsabilidad sobre la culpa del deudor, ya que esto resulta a todas luces absurdo). Cabe la aclaración en tanto hay quien ha sostenido que "el incumplimiento es tal sólo cuando es imputable; si no es imputable, en efecto, no puede hablarse de incumplimiento en sentido técnico. La expresión «incumplimiento no imputable", en efecto, constituye una contradicción de términos, porque el incumplimiento se califica técnicamente como violación de un deber (el deber de cumplir) y como tal lleva dentro de si, prescindiendo de otras circunstancias, la indefectible razón de su propia imputabilidad. Ante ello, y con el fin de sustentar la idea, citemos la aclaración terminológica de un conocido autor subjetivista, que realmente resulta sintomática, en el sentido de que si el cumplimiento es la correcta ejecución de la prestación debida, el incumplimiento será la incorrecta o la falta de ejecución de la prestación misma; que tal falta de ejecución o su defectuosidad, sea imputable o, bien, inimputable, no le quita que el hecho sobre el que recae dicha calificación tenga la categoría de incumplimiento" (GIORGIANNI, Michele. $L$ inadempimento. 3.a ed. Milán: Dott. A. Giuffrè Editore, 1975, p. 860).

18 Cabe efectuar en este punto un deslinde con la fattispecie del artículo 1149 del Código Civil. Este supuesto, a nuestro entender, es más amplio, pues compromete tanto a los casos en que el tercero actúa como instrumento del cumplimiento, bajo la dirección del deudor (así tenemos el caso de los auxiliares que el deudor utiliza en el cumplimiento, ex artículo 1325 del Código Civil), como en los que el tercero actúa libremente, por iniciativa propia, como en la figura analizada. Sin embargo, tal norma será de utilidad para la construcción de las reglas de operatividad del "cumplimiento" del tercero, sobre todo en lo que concierne a sus límites.

19 La opinión vertida se corresponde con la posición esbozada por las llamadas teorías patrimoniales, según las cuales, como es conocido, en la obligación el «objeto del derecho del acreedor es el bien debido y/o el resultado de la prestación, no ya esta última, entendida como comportamiento del deudor". DI MAjO, Adolfo. "Dell'adempimento in generale. Libro Quarto. Delle obbligazioni (artt. 1177-1200)». Op. cit., p. 47. 
de la imputabilidad del incumplimiento, pues ello importa un problema de responsabilidad no atinente a nuestra investigación.

No es correcto, sin embargo, observar el cumplimiento exclusivamente como un comportamiento del deudor, comportamiento que, se dice, debe ser conforme al programa negocial. El interés del acreedor, desde este punto de vista, no determinaría el contenido del cumplimiento (del deudor) en tanto pueden verificarse casos en los cuales, no obstante el deudor se haya comportado correctamente (por lo que no podrá ser considerado incumplidor), aquel no se ha visto satisfecho (como, por ejemplo, se tiene en el caso del médico que se empeña en curar un paciente sin conseguirlo); y porque, al contrario, existirían casos en los cuales el interés del acreedor es satisfecho, aunque el deudor no verifique el comportamiento prestacional, ${ }^{20}$ es decir, satisfacción fuera de la actividad del deudor, como se tendría en el cumplimiento del tercero.

Lo que sucede, en el caso del médico, es que existe una insatisfacción del interés concreto del acreedor pero no del interés abstractamente considerado. Este último, por demás, resulta valorable por encima del llamado interés concreto, ya que es indiscutible que el deudor (el médico) habría cumplido dentro de los parámetros de su obligación (de medios). ${ }^{21}$

Remarcando más aún la idea, se debe excluir de plano la identificación absoluta entre la actividad del deudor y la ejecución del programa prestacional. Solo cuando el deudor ejecute dicho programa podremos hablar estrictamente de cumplimiento, de una satisfacción indiscutible del interés (abstracto) del acreedor y propiamente de la extinción de la obligación. Cuando no haya una identidad subjetiva (deudor-tercero), podrá haber ejecución del programa y satisfacción del interés, pero supeditado a que el acreedor no tenga una justificación para rechazar el ofrecimiento del tercero. Tampoco debemos identificar la realización del programa prestacional con la satisfacción del interés del acreedor, según se ha dicho. ${ }^{22}$

20 La idea es de Nicoló, Rosario. "Adempimento". Enciclopedia del Diritto. Vol. I. Milán: Dott. A. Giuffrè Editore, 1958. En idénticos términos: FranCESCHETTI, Paolo. Obbligazioni e responsabilitá civile. Verona: Edizioni Simone, 1996, pp. 81-82.

21 Así, en las obligaciones de medios o de actividad, el deudor estaría constreñido a observar una conducta diligente, a conducirse de la manera más idónea para intentar obtener el resultado esperado, claro que según el standard prefigurado, mientras que, en las obligaciones de resultado, el deudor estaría constreñido a la obtención específica de un resultado (opus) y solo concretándolo en la realidad se liberaría. La diferencia radica en la mayor o menor amplitud de lo debido respecto del interés primario del acreedor, consistente siempre en un resultado. Lo que sucede es que el "grado de cooperación" del deudor es distinto.

22 Ya hemos expresado nuestra postura (PALACIOS Martinez, Eric e Ysmael NúNez SÁEnz. Teoría general de las obligaciones. 1.2 ed. Prólogo de Gastón Fernández Cruz. Lima: Jurista Editores, 2004, p. 167 y ss.), que se apoya sobre la inconveniencia de afrontar la 


\title{
2. La fattispecie del artículo 1222 del Código Civil: precisiones con- ceptuales y sus intrínsecas limitaciones de operatividad
}

\author{
La fattispecie (supuesto de hecho legal) contenida en el artículo 1222 del \\ Código Civil recoge o, mejor dicho, permite lo que en la doctrina se ha
}

problemática del incumplimiento a través de la generación de una tipología del incumplimiento o de las defectuosidades del cumplimiento, como se ha hecho patente en las construcciones más consistentes; luego de esto, debería acogerse como incumplimiento solo la falta absoluta de la prestación debida $y$, como "cumplimientos inexactos», todas las vicisitudes que se puedan presentar en la ejecución de la prestación, que no signifiquen su ausencia absoluta. Entendemos necesario, sobre todo en lo que concierne a la opción tomada por el Código Civil, establecer una suerte de tarea clasificatoria de los mismos, atendiendo, o tomando como criterios de referencia, a las que personalmente llamaremos reglas del cumplimiento, que han sido recogidas en nuestra codificación y que fluyen, concretamente, de la preceptiva de los artículos 1220, 1221 y 1240 del Código Civil. Así tenemos que, en nuestra opinión, se puede aceptar la existencia de los siguientes principios:

a) regla de integridad,

b) regla de identidad $y$

c) regla de oportunidad.

En este orden, se debe acotar que la regla de integridad supone que la ejecución de la prestación no puede ser cuantitativamente separada en el sentido de que el deudor debe de ejecutarla, dentro de lo previsto en el coritenido, totalmente y no por partes. De ello se deduce que el acreedor puede rechazar una prestación que sea cuantitativamente inferior al contenido de la obligación; aunque se trate de una prestación que sea susceptible de fraccionamiento (divisibilidad objetiva), es posible que cada una de las partes sea capaz de conservar proporcionalmente el valor y la función económica del entero cumplimiento (BreCCIA, Humberto. Op. cit., p. 400).

Por otro lado, la regla de identidad implica que la prestación debe reunir las características plasmadas en el contenido del hecho generatriz de la obligación; en estos supues. tos están incursos tanto los casos de prestación diversa como de prestación estrictamente defectuosa, los que son reconducibles a una defectuosidad genérica en la forma de cumplir. Es un supuesto de inexactitud cualitativa de la prestación.

La regla de oportunidad se concreta, por último, en las circunstancias del cumplimiento, es decir, el lugar y el momento de cumplimiento según el programa prestacional sobre el que se desarrolla la relación obligatoria.

Nuestro Código Civil en su articulado se refiere a tres tipos de cumplimientos inexactos, el parcial, el defectuoso y el tardio, los que pueden, y deben, considerarse como transgresiones de cada una de las reglas enunciadas. El cumplimiento parcial deriva de transgredir la regla de integridad; el defectuoso, de transgredir la regla de identidad; $y$ el tardio, de transgredir la regla de oportunidad en su aspecto temporal.

A pesar de ello, y con la finalidad de lograr una sistemática coherente con el articulado del Código Civil, pues este reconoce enunciativamente solo la regla de integridad en el artículo 1220, debemos de propender a distinguir entre integridad cuantitativa (en sentido estricto) e integridad cualitativa, identificable con la regla de identidad, ya que, en el artículo 1221, se hace alusión al primero de los conceptos acotados en forma específica. En otros términos, el artículo 1220 recoge, en forma amplia, el concepto de integridad según esta clasificación, pero el artículo 1221 solo lo haría con respecto a la integridad cuantitativa. La integridad cualitativa, identificable con la identidad, según 
llamado como el cumplimiento del tercero, permisión que, vale ya decirlo desde un primer momento, tiene como principal objetivo la satisfacción del interés del acreedor. ${ }^{23}$

La primera impresión que nos causa el artículo en cuestión es que este resulta incompleto y confuso, con miras a resolver la problemática que hasta ahora hemos venido planteando. Es obvio que dicha norma, como casi todo el Libro de las Obligaciones, es de corte francés. Nótese cómo la legislación francesa, concretamente el artículo 1236 del Code Civil, es atenta todavía a que la posición del deudor no venga perjudicada por la intervención no solicitada del tercero. El Código francés distingue, al igual que el nuestro, entre tercero interesado y no interesado. Solo al primero es reconocida la posibilidad de intervención en cuanto titular de un legítimo interés al cumplimiento (tal el coobligado o aquel que haya dado una caución a favor del deudor). Para los terceros no interesados, se necesita demostrar la ventaja del deudor. Nuestra opción legislativa, a pesar de la anotada similitud, se aparta de tal orientación, ya que no otorga consecuencias expresas a la existencia o no de un interés en el tercero, las que deberán ser deducidas, sino que da relevancia inicial a la existencia o no de asentimiento por parte del deudor. Con respecto a la esfera de interés del deudor, la no existencia de asentimiento se considera decisiva solo para determinar la situación sucesiva del tercero que "cumple» la prestación. Parece, por lo lato de la mención a la falta de asentimiento del deudor, que, dentro de la misma, estaría comprendida también la oposición del deudor, lo que será examinado en los puntos siguientes. Se revela, por demás, cómo la norma por sí sola no resuelve los problemas innatos al desenvolvimiento de la actividad del tercero, tales como los límites $\mathrm{y}$, sobre todo, los efectos de la aludida oposición del deudor con miras a la tutela de su derecho de liberación. Será necesario, entonces, proceder a la construcción de la disciplina utilizando la normativa pertinente a fin de extraer del entero sistema las soluciones a los problemas planteados.

parecer propio, no se encontraría expresamente reconocida, sino indirectamente a través de la regla de integridad "general" del artículo 1220, de las normas de saneamiento por vicios ocultos (art. 1503 y ss.), así como de la propia normativa de la inejecución de obligaciones cuando se alude al cumplimiento defectuoso (por ejemplo, el art. 1314). En lo que concierne a la regla de oportunidad, de lugar y de temporalidad, ambas variantes están recogidas respectivamente en los artículos 1238 y 1240 del Código Civil.

23 Así se ha afirmado, en el marco normativo italiano, que "a través de la admisibilidad del cumplimiento del tercero, el legislador ha claramente demostrado, como se ha dicho, querer preferir el interés general de los acreedores a ver actuada la relación incluso por no-deudores respecto a aquel, eventualmente contrario, del particular deudor (y también del particular acreedor)". Nos referimos a DI MAJO, Adolfo. "Dell'adempimento in generale. Libro Quarto. Delle obbligazioni (arts. 1177-1200)». Op. cit., p. 70. 
La figura del cumplimiento del tercero, que para algunos operadores puede aparecer como de extrema simplicidad, desde el punto de vista teórico, nos lleva a un profundo problema dogmático: aquel de la intervención de un sujeto en la esfera jurídica ajena, por cuanto, además, se advierte que esta intervención se refiere al lado pasivo y no a aquel activo en el cual se vierte típicamente el ámbito del ejercicio de los derechos ajenos. En este último caso, el principio general es aquel de la irrelevancia de la actividad del tercero en los límites del titular del derecho, mientras las excepciones a este principio se justifican o en virtud de una legitimación del tercero derivada de un poder o de una situación jurídica particular. El fenómeno se reconduce, entonces, en el cuadro general de la disposición de relaciones instauradas entre terceros extraños (ajenos) al titular del derecho. ${ }^{24}$

Debemos acotar que el hecho de que el tercero tenga o no interés en el cumplimiento sí puede generar consecuencias que se enmarcan en la aplicación de la subrogación de pleno derecho o de la denominada "convencional» (inciso 2 del artículo 1260 e inciso 1 del artículo 1261 del Código Civil). La posibilidad de una subrogación siempre se tendrá presente, ya que, como se tiene que deducir, exista o no interés esta se puede producir. Así, si el tercero tuviera interés legítimo, aun cuando no tenga el asentimiento del deudor, se produciría la subrogación legal según lo dispuesto por el inciso 2 del artículo 1260 del Código Civil. El caso descriro en el segundo párrafo del arrículo 1222 Código Civil, atinente a la existencia de una obligación estrictamente restituroria, es aquel en que el tercero no tiene interés en el cumplimiento y, además, cumple sin asentimiento del deudor. Por ejemplo, un tercero interesado es el copropietario que cumple la obligación de otro copropietario con el fin de evitar la afectación del bien, o aquel propietario que ha hipotecado su casa para garantizar una deuda ajena; en otros términos, un tercero interesado es el que, al ejecutar la prestación, protege la realización de sus derechos subjetivos, que, de lo contrario, pueden verse lesionados. Pero volviendo al tema, cuando se alude a la posibilidad de que el tercero no interesado, que paga sin asentimiento del deudor, solo pueda exigir la restitución de aquello en que le hubiese sido útil el pago, lo que se quiere decir es que se dispone la restitución estricta de la ventaja patrimonial obtenida por deudor sin la intervención de ningún otro concepto (intereses o daños y perjuicios).

Volviendo al análisis de la norma, ya se ha precisado que la satisfacción del interés del acreedor puede ser conseguida aun sin la intervención direc-

${ }^{24}$ Es la posición de Miccio, Renato. «Delle obbligazioni in generale (artt. 1173-1320)». En Commentario del Codice Civile. 3. ${ }^{a}$ ed. Libro IV. T. I. Título I. Turín: UTET, 1982, p. 88. 
ta ni indirecta del deudor como sujeto constreñido a la ejecución de la prestación debida. La incorporación de este mecanismo, en otros términos, implica la admisibilidad de la ejecución de la prestación por obra de un sujeto distinto del deudor, sea dentro de los límites contextualmente y específicamente delimitados por el legislador en la misma norma o dentro de aquellos parámetros que puedan deducirse del entero sistema. ${ }^{25} \mathrm{La}$ justificación de esta figura encuentra sustento en una función solutoria, que se manifiesta en la fase de actuación de las obligaciones. ${ }^{26}$

El debate dogmático, entonces, se centra en la admisibilidad de la prestación "cumplida" por el tercero con respecto al cumplimiento "normal" del deudor; para ello, se toma, como ya se dijo, en consideración el aspecto funcional de la relación obligatoria y no el aspecto estructural, pues, con este último, existe una incompatibilidad en cuanto la prestación solo podría ser cumplida estrictamente por el deudor. Sobre esto, sin perjuicio de lo expuesto, precisemos, a manera de resumen, que el "cumplimiento" del tercero, al igual que el efectuado por el deudor, también debe valorarse tomando el criterio contenido en la cláusula general de exacto-inexacto cumplimiento, delimitada por la más coherente doctrina, ${ }^{27}$ en el sentido de que el cumplimiento del tercero debe ser, por lo menos, objetivamente idéntico al que hubiere realizado el deudor, ya que, de no ser así, se incurriría en una trasgresión de los derechos subjetivos del deudor; específicamente aquel derecho de liberarse normalmente frente al acreedor originario (apoyada en una situación jurídica subjetiva de desventaja activa-débito). Por otro lado, el acreedor puede, no debe, aceptar del tercero la ejecución de una prestación inexacta, bajo el perfil cuantitativo (cumplimiento parcial), en igual forma que le hubiese sido permitido consentírsela al propio deudor si se utilizara el argumento a contrario contenido en el artículo 1221 del Código Civil. Si ahondamos un poco en esta última norma citada, podremos extraer el problema de si el acreedor que ha aceptado un cumplimiento parcial del tercero podría dirigirse al deudor por la parte de la prestación pendiente. Sobre esto, nos parece propicio optar por la solución negativa en cuanto el acreedor que discrecionalmente, al igual que lo pudo haber hecho con el deudor, permite que el tercero efectúe parcialmente la prestación a él debida asiente en que su crédito se verá satisfecho con dicho acto: mal, entonces, podría

25 RESCIGNO, Pietro. «Ripetizione dell'indebito». Novísimo Digesto Italiano. T. XV. Turín: UTET, 1968, p. 1230. Esta idea nos servirá de soporte para llenar los vacíos existentes en la descripción normativa del fenómeno que nos atañe.

26 BRECCIA, Humberto. Op. cit., p. 437.

27 Baste como ejemplo citar a NiCOLÓ, Rosario. «Adempimento». Op. cit., p. 562 y ss. 
dirigirse contra el deudor, que incluso pudo verse afectado con la intervención del tercero.

En este orden de ideas, se ha señalado que la regla de la "exactitud" del cumplimiento puede tener dos perfiles: el objetivo, vinculado a la conformidad de la prestación ejecutada con el contenido de la obligación que pesa sobre el deudor; y el subjetivo, conectado a la identidad de los sujetos inmersos en la ejecución y, en particular, a la persona (parte) llamada a cumplir. ${ }^{28}$ El primero, ya desde nuestra perspectiva, tiene indudable relevancia en el plano de la verificación del cumplimiento y del eventual surgimiento de la responsabilidad como consecuencia de la falta de exactitud; el segundo - no obstante que parece haber sido considerado irrelevante con el reconocimiento del cumplimiento del tercero o, más aún, con la concesión de una legitimidad genérica para el cumplimiento - se denota cuando la primera parte de la fattispecie acotada señala que puede hacer el pago cualquier persona, tenga o no interés en el cumplimiento de la obligación, sea con el asentimiento del deudor o sin él.

Dados los límites del presente estudio, valga indicar que, para que se pueda hablar de cumplimiento de tercero, no basta, sin embargo, la objetiva realización del interés del acreedor y la voluntad de cumplir la prestación en ventaja del accipiens, sino que es necesario que el cumplimiento sea referido, de algún modo, a la relación efectivamente existente entre deudor y acreedor. ${ }^{29}$ En el cumplimiento del tercero, se ha dicho, la actividad del solvens, que es siempre libre, está dominada por un expreso elemento volitivo: el animus de referir la prestación a una relación obligatoria en la cual el tercero es consciente de ser extraño. ${ }^{30}$

\section{Los límites del cumplimiento del tercero. El interés del acreedor en el cumplimiento "estricto» del deudor. El interés del tercero por cumplir}

Ahora bien, es evidente que la configuración de una legitimidad genérica para el cumplimiento puede estar supeditada a la anuencia del acreedor, que, en ciertos casos, justificadamente rechaza la actividad del tercero dirigida al cumplimiento. Esto es lo que la mayoría de la doctrina identifica

28 La idea es acogida por Turco, Claudio. Op. cit., pp. 23-24.

29 Es la impostación acogida por MOSCATl, Enrico. "Indebito soggettivo e attuazione del rapporto obbligatorio", trabajo ahora recogido en el volumen Fonti legali e fonti "private" delle obligazioni. Padua: CEDAM, 1999, p. 108.

30 MOSCATI, Enrico. "Pagamento dell indebito, adempimento del terzo e legittimazione a ripetere la prestazione». En Fonti legali e fonti "private» delle obligazioni. Op. cit., p.76. 
como límites del cumplimiento del tercero, sustentada en el interés contrario del acreedor o del deudor, que aparece vinculado principalmente al perfil concerniente a la personalidad de la prestación o, en otros términos, a la exigencia de una ejecución personal. ${ }^{31}$

Es claro que uno de tales límites se concreta cuando el interés del acreedor no se ve satisfecho con la actividad del tercero porque su interés se dirige a que el deudor ejecute personalmente la prestación. El acreedor puede rechazar que otro sustituya al deudor en el cumplimiento toda vez que el acreedor tenga un interés en la ejecución personal de la obligación por parte del deudor. ${ }^{32}$ Incluso, algún autor considera que el único límite que encuentra el cumplimiento del tercero es aquel constituido por la existencia de un interés del acreedor a que el deudor ejecute personalmente la prestación. ${ }^{33}$ Generalmente, se identifican estas prestaciones como contenido de las denominadas obligaciones intuito personae. Tenemos como ejemplos de estas obligaciones el retrato del célebre pintor, el reconocido prestigio de ciertas empresas constructoras en la edificación de viviendas familiares, la atención de un determinado profesional médico o abogado para tratar asuntos judiciales de orden personal o afectivo y, en general, todas aquellas prestaciones que requieren competencia y pericia específicas. La valoración particular del contenido de la relación obligatoria, según los lineamientos expuestos en la parte introductoria, ayudarán a evaluar la naturaleza "personal" de la prestación por ejecutarse en cada caso, máxime cuando se desborda la tipicidad del interés y se tiene que recurrir a lo que se ha llamado causalización del motivo. Es interesante cómo la doctrina alemana nos informa de ciertos tipos negociales en los que, por disposición legal

3 Di MAJO, Adolfo. "Dell'adempimento in generale. Libro Quarto. Delle obbligazioni (artt. 1177-1200)». Op. cit., pp. 59-60. Aleccionadoras, con respecto a la intrínseca necesidad de límites en la actuación del tercero en el cumplimiento, son las palabras de Alberto Trabucchi: "¿Quién puede cumplir? Quien debe cumplir es siempre el deudor. Según el art. 1180 también un tercero cualquiera puede pagar por él, incluso contra la voluntad del acreedor, cuando se trate de prestación infungible sobre la cual el acreedor tenga un interés objetivamente valorable de verla cumplida personalmente por el deudor", y agrega a pie de página que "es de apreciar que el pago del tercero se caracteriza por la conciencia de éste de ser extraño a la relación obligatoria (animus). $\mathrm{Si}$, en efecto, el tercero estuviese convencido de ser deudor se configuraría una hipótesis de indébito subjetivo". (TRABuCCHI, Alberto. Istituzioni di Diritto Civile. 41. a ed. Editado por Giusseppe Trabucchi. Padua: CEDAM, 2004, p. 647; en nuestro medio es conocida la traducción efectuada por el español Luis Martínez-Calcerrada, publicada por la Editorial Revista de Derecho Privado de Madrid en 1967, que consta de dos tomos.

32 INZITARI, Bruno. Op. cit., p. 441.

33 Di MAJO, Adolfo. "Dell'adempimento in generale. Libro Quarto. Delle obbligazioni (artt. 1177-1200)». Op. cit., p. 59. 
expresa, en caso de duda, la prestación debe ser ejecutada por el deudor en persona. $^{34}$

En nuestra realidad normativa parece que el asunto se ha tomado en un sentido nominalmente inverso, pero se ha llegado al mismo resultado que se logra, por ejemplo, en el ordenamiento italiano, puesto que el artículo 1222 del Código Civil ha configurado como regla la legitimación genérica para cumplir, a la cual solo excluye cuando la naturaleza o el pacto, que puede ocurrir en cualquier momento entre las partes originarias, ${ }^{35}$ no lo permitan. El término "naturaleza", contenido en el primer párrafo del artículo, permite tomar en consideración tanto el interés del acreedor en que sea el mismo deudor el que cumpla con la prestación, como las caracteristicas de la prestación que podrían justificar la negativa al cumplimiento del tercero. Apoya clarísimamente el límite analizado el tenor del artículo 1149 del Código Civil, que permite in genere la ejecución de la prestación por un tercero, no importa si actuando por encargo del deudor o autónomamente, a no ser que del pacto o de las circunstancias resultara que este fue elegido por sus cualidades personales. La lógica de esta norma informa, por su amplitud, también a la figura del cumplimiento del tercero y nos confirma cómo la tutela del interés del acreedor se ve defendida en las hipótesis en las que el origen de la relación obligatoria tiene como sustrato la ejecución personal del deudor.

Parte de la doctrina para caracterizar este límite de actuación del tercero ha construido la figura de las prestaciones infungibles caracterizadas porque sobre ellas existe un interés del acreedor a recibir la prestación personalmente por el deudor. El interés debe ser apreciable objetivamente, ya que tal valoración no se restringe a las hipótesis en las cuales tenga relevancia la competencia profesional o la organización empresarial de quien se prepare a ejecutar la prestación, sino que se extiende a todos los casos de menor seguridad sobre el resultado final. ${ }^{36}$

34 LARENZ, Kart. Derecho de Obligaciones. Trad. de Jaime Santos Briz. T. I. Madrid: Editorial Revista de Derecho Privado, 1958, pp. 254-255, quien textualmente señala: «Algunas prestaciones sólo pueden ser realizadas personalmente por el deudor porque dependen de su habilidad especial, de sus conocimientos técnicos, de su reputación o de sus características personales. La ley establece que en la duda han de ser cumplidos personalmente: la obligación del deudor o empresario en el contrato de servicios, la del mandatario, la del socio, la del depositarion (hemos suprimido la referencia a la normativa alemana por considerarla superflua).

35 En nuestra opinión, el pacto contenido en una cláusula determinada puede dirigirse tanto a la precisión de que la prestación por ejecutarse tiene la naturaleza intuito personae, como a la oposición anticipada del deudor a que otro sujeto ejecute la prestación a su cargo, sin expresión alguna en torno a la naturaleza de la misma.

36 BIANCA, Massimo. Op. cit., p. 284. Es por demás interesante la propuesta de Di Majo, que distingue entre las prestaciones intrínsecamente definidas por sí mismas como infungibles 
Queda por añadir que este límite para el cumplimiento del tercero no solamente es aplicable, al menos teóricamente y como pudiera parecer, a las obligaciones de hacer - es claro que, en este tipo de obligaciones, el interés abstracto del acreedor puede fundar la facultad de rechazo del acreedor en tanto este se desprende de características objetivas de la prestación-, ya que, en el fondo, se debe dar prevalencia genérica al interés digno de tutela, aunque no necesariamente se encuentre vinculado a las características de la prestación. Sin embargo, el artículo 1222 del Código Civil, al hacer mención expresa a la naturaleza de la prestación, parece restringir dicha posibilidad a las prestaciones que objetivamente puedan ser tomadas como infungibles, que, en bastantes casos, se identifican con las obligaciones de hacer.

En buena cuenta, dentro de la hipótesis, el acreedor puede rechazar el "cumplimiento" del tercero si tiene un objetivo interés en que el deudor cumpla personalmente la prestación.

Importante es, aunque ello no sea materia de nuestra indagación, incidir concretamente en que la intervención del tercero debe, dentro de la fenomenología analizada, ser espontánea, en el sentido de que no debe ser provocada por una actividad del deudor, ya que, en este caso, nos encontraríamos ante una directiva de este último, lo que la aparta de la hipótesis del cumplimiento de un débito ajeno. El tercero, en nuestro caso, cumple autónomamente, es decir, sin ser representante, gestor, mandatario, auxiliar, etc. del deudor; en otros términos, no encamina su actividad a la liberación del deudor, sino, primigeniamente, a la satisfacción del interés del acreedor, por lo que, para los efectos de la existencia de la fattispecie, es irrelevante la concurrencia de un interés en dicha actividad solutoria a favor del deudor. ${ }^{37}$ Aquí tal vez encontremos una diferencia precisa entre el cumplimiento del deudor y la ejecución del tercero: la actividad del tercero es

(infungibilidad objetiva) y las prestaciones contenidas en contratos concluidos intuito personae, cuya aplicación concreta corresponde a los jueces a través de un poder de apreciación del interés creditorio, que sirve como límite a la espontánea intervención de terceros en relaciones que vinculan a otros sujetos (Di MAjO, Adolfo. "Dell'adempimento in generale. Libro Quarto. Delle obbligazioni (artt. 1177-1200)". Op. cit., p. 62).

37 En este punto no estamos de acuerdo con la posición de Di Majo, para quien el cumplimiento del tercero implica una particular forma de sustitución in executivis en el cumplimiento de la singular obligación (D/ MAJO, Adolfo. "Dell'adempimento in generale. Libro Quarto. Delle obbligazioni (artt. 1177-1200)n. Op. cit., p. 62). Nos parecen interesantes las ideas de Miccio, Renato. Op. cit., p. 90 cuando señala que ael cumplimiento del tercero no presenta, por ende, ninguna identidad con el cumplimiento del deudor, dada la infungibilidad lógica de la prestación, ya que produce para el acreedor sólo un subrogado en el cumplimiento. Esta tesis, que me parece del todo aceptable, importa, si no yerro, mi convencimiento que el cumplimiento del débito ajeno constituya, no sólo una intervención autónoma, sino externa e independiente, adquiriendo todo el aspecto de una disposición de la relación, el cual muta sus términos por actividad unilateral». 
libre, es decir, en ella no media ningún deber de constricción que le dé contenido, mientras que la actividad solutoria del deudor es calificada, por la doctrina especializada, como un acto debido. ${ }^{38}$

Más interesante es detenerse sobre aquel otro límite al cumplimiento del tercero, al menos así catalogado por nuestra parte, que confiere al acreedor, ya lo dijimos, la facultad de rechazar justificadamente la oferta del tercero: nos referimos al supuesto de la oposición del deudor.

Por último, en este punto, quisiera dejar establecido que los límites del cumplimiento del tercero guardan una importancia trascendental en el aspecto práctico, ya que constituyen la única justificación para el rechazo de la prestación del tercero, el mismo que, de no existir ninguna justificación, podría atenerse al procedimiento de liberación coactiva, identificado en nuestro ordenamiento en el pago por consignación, exartículos 1251 y ss. del Código Civil. Y es que, a falta de un interés objetivamente relevante para la ejecución de la prestación por parte del deudor o debido a la oposición del deudor, el acreedor no puede rechazar el cumplimiento del tercero, con la consecuencia de que la ilegitimidad del rechazo a la prestación del tercero impide al acreedor actuar contra el deudor. ${ }^{39}$ Con la justificación otorgada solamente por los casos de limitación, se rompe la regla general reflejada en la legitimación genérica reconocida por el artículo 1222 del

Contra la alegada absoluta falta de identidad entre el cumplimiento del deudór y del tercero se ha pronunciado expresamente CANNATA, Carlos Augusto. "L'adempimento delle obbligazioni». En Trattato di diritto privato diretto da Pietro Rescigno. Vol. 9. T. I. Turín: UTET, 1984, p. 79, en los siguientes términos: «se ve rápidamente la dificultad que tal posición comportaría, solo pensando que, donde la prestación debida tenga por objeto la atribución de un derecho, la ejecución operada por un tercero, si no fuese considerada cumplimiento, adolecería de la conexión con la obligación que, suministrando la causa de la atribución, hace posible la transferencia o la constitución del derecho mismo". A nuestro parecer, lo que sucede es que la transferencia del derecho se produciría desde una esfera distinta a la del acreedor: la del tercero, lo que importaría un mecanismo de adquisición distinto al que se produciría por la actuación del deudor.

38 Para una demostración de que el cumplimiento es un acto debido ver el interesante trabajo de NATOLI, Ugo. "Adempimento, atto dovuto, negozio giuridico". En Scritti in onore di SAlvatore PuCliattı. Presentación de Rosario Nicoló. Vol. I. T. II. Milán: Pubblizazioni dell'Istituto di scienze giuridiche, economiche, politiche e sociali della Universitá di Messina, Dott. A. Giuffrè Editore, 1978, p. 1532 y ss.; en el que se puede leer, con relación al cumplimiento del deudor: «La característica constante está representada por la calificación de necesidad, que cubre infaltablemente el comportamiento del deudor. En cuanto dirigido al cumplimiento, tal comportamiento es siempre debido. Ello no excluye, sin embargo, que en concreto, este pueda presentarse con la diversa estructura del comportamiento material o del acto jurídico, o, a su vez, asumir, según los casos, el ropaje de negocio jurídico, o de momento estructural de una fattispecie negocial compleja cual es el contrato". 
Código Civil. ${ }^{40}$ En síntesis, la posibilidad del acreedor de rechazar la oferta del tercero se presentaba, en tal modo, del todo excepcional, limitada, como se ha visto, a ciertas categorías de relaciones y en conexión con el objetivo carácter de infungibilidad de la prestación del deudor. ${ }^{41}$

\section{La oposición del deudor. El derecho del deudor a la liberación.}

Llegados a esta instancia, dejándose ya entrever nuestros lineamientos de enfoque del "cumplimiento" del tercero, es momento oportuno de abordar la temática que ha dado origen a la investigación efectuada. Nos referimos a la conexión existente entre el denominado derecho a la liberación del deudor, atinente a la dinámica general de la relación obligatoria (lo que desborda inclusive nuestra temática), y la eventual oposición del deudor al cumplimiento del tercero. Dicha problemática adquiere matices de interés sobre todo porque no existe aparentemente ningún apoyo en el derecho positivo que nos permita determinar una posición concreta sobre el particular.

El derecho de liberación del deudor puede, primeramente, estar apoyado en una situación jurídica subjetiva de desventaja activa que es imperativo, para el deudor, remover. No puede ser indiferente para el deudor el modo a través del cual consigue la liberación, lo que, según algunos autores, no se restringe a un aspecto pura y abstractamente ético, ya que, en el fondo, lo que se desea constatar es si el ordenamiento considera relevante el interés del deudor por conseguir la liberación; así, se destaca la necesidad de la atribución de un derecho potestativo. ${ }^{42}$ La doctrina ha puntualizado

40 De acuerdo con Di MAJO, Adolfo. "Dell'adempimento in generale. Libro Quarto. Delle obbligazioni (artt. 1177-1200)». Op. cit., p. 60, quien expresamente señala que "corresponde a todo tercero, en plena autonomía y libertad el cumplir la obligación ajena, incluso contra la voluntad del acreedor, siendo por tanto una carga (onere) de éste recibir el cumplimiento también del tercero".

41 No se da, entonces, una relevancia autónoma al interés del acreedor desconectada de los parámetros objetivos señalados por la norma. Así, desde nuestra normatividad, es dudoso que sea legítimo el rechazo al cumplimiento ofrecido por un tercero que sea un empresario en estado de insolvencia, por el riesgo que tal pago correría, en el sentido de poder ser impugnado. El caso, citado por Giorgianni, nos lo hace saber CANNATA, Carlos Augusto. Op. cit., p. 81.

42 Sobre el particular NATOLI, Ugo. "L'attuazione del rapporto obbligatorio". En Trattato di Diritto Civile e Commerciale. Fondato dai professori Antonio Cicu e Francesco Messineo, continuato da Luigi Mengoni, e ora directo da Piero Schlesinger. Vol. XVI. T. 1. Milán: Dott. A. Giuffrè Editore, 1974, p. 65, afirma: "Conviene relevar que la tutela del interés del deudor estaría más que asegurada cuando a éste le fuera ofrecido el medio idóneo, que además de hacerle conseguir la liberación del vínculo, le permita también constatar, en definitiva, que él ha efectuado todo cuanto estaba constreñido a hacer a efectos de verificar un exacto cumplimiento y la consecuencial realización del interés del 
que, en el tentativo de reconstruir la posición del deudor en forma integral, se hace referencia a peculiares "derechos" que acompañarían el deber en la fase del cumplimiento. Estos "derechos" encuentran, en la hipótesis del alargamiento de la relación derivado de un abuso del acreedor, un ejemplo plausible, pero que revela no tanto un derecho del deudor al cumplimiento sino más bien un derecho a liberarse, si es necesario, en forma diversa al cumplimiento. ${ }^{43}$ De esta forma, se denota que, antes de que se verifique la situación moratoria creditoria, el derecho a liberarse se reabsorbería en el comportamiento debido. ${ }^{44}$

Acerca de la oposición del deudor - se entiende a que otro sujeto cumpla la prestación a su cargo-, se ha discutido en torno a su incidencia en el desenvolvimiento de la relación obligatoria en lo que concierne a la legitimación que conferiría al acreedor para rechazar la oferta del tercero a cumplir.

Así, por un lado, se había señalado que dicha oposición debía de considerarse irrelevante, por lo que el acreedor no podría, solo por tal hecho, rechazar la oferta del tercero. ${ }^{45}$ La posición contraria, también extrema, sostenía que, como consecuencia de la oposición, el acreedor quedaba impedido de aceptar la oferta del tercero; quedaba, por ello, constreñido a

acreedor. A tal efecto, más que el recurso al esquema de una obligación, aunque sea accesoria y marginal a cargo del acreedor, parecería más acorde el reconocimiento al deudor de una posición típicamente instrumental tal como el derecho potestativo». solución que se refleja en los institutos de la mora del acreedor y de la liberación del deudor independientemente de toda cooperación o, por añadidura, contra la voluntad del acreedor. De acuerdo: BARASSI, Ludovico. La teoria generale delle obligación. T. III. Milán: Dott. A. Giuffrè Editore, 1948, p. 92.

43 BRECCIA, Humberto. Op. cit., p. 457.

44 lb. Sobre esto último, no nos encontramos de acuerdo, puesto que, en el caso del cumplimiento del tercero, la problemática puede desarrollarse antes de la dinámica del comportamiento debitorio en sí mismo considerado. En otras palabras, el tercero debe cumplir antes que la obligación se torne en exigible. La respuesta en este punto es clara, ya que la subrogación y/o restitución se plasmarán sobre lo que haya sido de utilidad para el deudor.

45 CARBONI, M. Della obbligazione nel diritto odierno. Concetto e contenuto. Turín: Edizioni Bocca, 1912, p. 196 y ss. Esta posición se sustenta en que al tercero se le reconoce un derecho de cumplir la obligación ajena, de lo que deriva que la oposición del deudor no tendrá efecto. Son los casos en que se ha reconocido un Ablösungsrecht al tercero, donde el acreedor se dispone a efectuar actos de expropiación sobre los bienes del deudor, respecto a los cuales el tercero corre el riesgo de perder un propio derecho. Corresponde a todo tercero, en plena autonomía y libertad, según esta tesis, el cumplir la obligación ajena, incluso contra la voluntad del deudor.

Sin embargo, ella resulta contradictoria, pues el tercero, ante, por ejemplo, la oposición del deudor (irrelevante), tendría derecho de recurrir al procedimiento de liberación coactiva, lo que daría como incoherente resultado que el deudor se vea favorecido aun cuando se haya opuesto expresamente a ello. Así, se violenta el principio según el cual se puede rechazar beneficios no solicitados de origen anglosajón. 
rechazarla. ${ }^{46}$ Una posición intermedia, reseñada con anticipación, acogida incluso por el Codice Civile italiano de 1942, deja al acreedor en la elección de aceptar o no la oferta del tercero. ${ }^{47}$ Desarrollando esta última idea, se ha señalado que el acreedor tiene la facultad, no el deber, de rechazar el cumplimiento cuando el deudor le haya manifestado su oposición (por ejemplo, el deudor no quiere que sus deudas sean pagadas por un conocido personaje de pasado "poco honesto", por un adversario político o por un odiado competidor). ${ }^{48}$

Vital para establecer algún lineamiento que ayude a resolver la problemática es precisar que, con el cumplimiento del tercero, el deudor no necesariamente se verá liberado, ya que, de todas formas, este podría estar atado a una situación de deber frente al tercero, como ocurriría ante la presencia del fenómeno subrogatorio. Conectando el derecho a la liberación con la oposición del deudor al "cumplimiento del tercero», esta última como inserta dentro de dicho derecho, nos daremos cuenta de que, también en la señalada hipótesis, el deudor tiene un interés en liberarse tempestivamente mediante el cumplimiento que constituye la manera normal en que el crédito (no solo el interés del acreedor) puede obtener satisfacción. La satisfacción del interés del deudor a la regular actuación de la relación obligatoria y, por lo tanto, a su liberación no depende, sin embargo, solamente de su comportamiento, sino que presupone también la colaboración del acreedor en recibir el pago o en hacer lo indispensable para que el deudor cumpla la prestación. ${ }^{49}$ Puede exitosamente argüirse tal orientación en nuestro ordenamiento remitiéndose a la normativa del pago por consignación o de mora del acreedor (considerando, por ejemplo, la ratio del motivo legítimo de rechazo). Así como el acreedor debe oponer un motivo legítimo para rechazar el cumplimiento del deudor - como lo manda el artículo 1338 del Código Civil-, en igual forma debería justificar la intromisión del tercero. El acreedor no puede actuar sin considerar el interés del deudor: lo contrario daría lugar a un comportamiento abusivo.

46 Era la posición de BORSARI. Commentario del Codice Civile Italiano. III, 2. Turín, 1877, p. 616, citado por NATOLI, Ugo. "L'attuazione del rapporto obbligatorio». Op. cit., p. 187.

47 Según NiCOLO, Rosario. L'adempimento dell'obbligo altrui. Op. cit., p. 254 (nota 19). Por demás, esta es la solución acogida por el $\$ 267$ del B. G. B (Código Civil alemán).

48 INZITARI, Bruno. Op. cit., p. 441.

49 En términos más o menos precisos, BIGLIAZZI GERI, Lina. "Interesse legittimo: diritto privato", trabajo que ahora se encuentra en el compendio de estudios Rapporti giuridici e dinamiche sociale. Principi, norme, interessi emergenti. Scritti giuridici. Milán: Dott. A. Giuffrè Editore, 1998, pp. 75-76; es bastante peculiar la idea propugnada por la autora al intentar asimilar el derecho a la liberación del deudor en la categoría del interés legítimo que formaría parte de las situaciones jurídico subjetivas tuteladas por el ordenamiento. 
El acreedor debería preferir el cumplimiento del deudor que el del tercero, máxime cuando se presenta una oposición a una intervención externa.

Así, la vinculación entre el derecho a la liberación del deudor y la oposición de Este a que un tercero cumpla una prestación a su cargo puede efectuarse considerando la tutela del interés del deudor a liberarse por su propia actividad y evitar que un tercero pueda ilegitimamente interferir en la dinámica de la relación obligatoria planteada entre él y el acreedor. No obstante ello, es propicio tomar en consideración que la tutela de tal interés tendrá lugar cuando, nos parece, se haya anticipadamente pactado, en forma expresa, por ejemplo en el negocio jurídico que origina la relación obligatoria, la exclusión de que cualquier tercero cumpla la prestación debida frente al acreedor. ${ }^{50}$ Sino se pactara ello, prevalecería la necesidad de que el interés del acreedor sea satisfecho incluso por medio de un tercero a través de un cumplimiento heteroeficaz, es decir, aquel cumplimiento que, actuando el contenido del derecho de crédito, no extingue, sin embargo, la obligación del deudor.

La cláusula negocial que contenga la prohibición de un cumplimiento heteroeficaz es, sin lugar a duda alguna, una cláusula lícita, válida y, por ende, tutelable, ya que no es sino una regla derivada de la autonomía privada de los sujetos involucrados que no atenta contra ninguna norma imperativa, ni contra los principios que informan al orden público y las buenas costumbres; es más, puede marcar incluso la existencia de un motivo casualizado (interés) prevalente en la específica relación obligatoria. Cuando el artículo 1222 del Código Civil alude al pacto como excepción a la legitimidad genérica, deja abierta la posibilidad de que el contenido del mismo sea una oposición expresa común al "cumplimiento» del tercero.

El rechazo a la prestación ejecutada por el tercero se torna, entonces, "debida» si la oposición, aceptada por el acreedor y plasmada, claro, en un pacto dirigido a resguardar el interés del deudor, tiene el carácter de anticipada, es decir, prevista en el contrato (negocio) entre acreedor y deudor, que adquiere la categoría de fuente de la obligación por cumplir. Discutible es la posibilidad de que el acreedor, aun mediando dicha estatuición, acepte la ejecución del tercero, claro está, que resarza el eventual daño al deudor.

Sin perjuicio de lo expuesto, que directamente fluye del artículo 1222 Código Civil, es menester reconocer, en aplicación del razonamiento que antecede, que la oposición del deudor puede ser tomada también como el

50 Sobre el particular, se ha señalado enfáticamente que «no puede en ningún caso prevalecer la voluntad del tercero sobre la concorde voluntad de los titulares de la relación obligatoria». Es el parecer de BESSONE, Mario y Andrea D'ANGELO. "Adempimento". Enciclopedia giuridica Treccani. Vol. I. Roma: Istituto della Enciclopedia Italiana, 1988, p. 6 (de la separata). 
punto de inicio de la exclusión del tercero, ya que permitiría que el acreedor se pliegue a esta oposición y rechace la iniciativa del tercero. Se tendría, en suma, un acuerdo posterior a la fuente, en este caso negocial, de la obligación susceptible de ser cumplida por el tercero. Ciertamente, el texto del artículo anotado permite efectuar tal interpretación, que, por cierto, se condice con las modernas orientaciones acerca de la temática expuesta, pues no especifica si el pacto a que se refiere su exclusión es uno de carácter inicial o posterior, como es el supuesto hipotéticamente descrito. La oposición del deudor marca, entonces, una declaración que puede ser sucesivamente completada por una declaración (comportamiento) del acreedor sin necesidad de que exista alguna justificación que apunte hacia la objetiva prestación, en el sentido de rechazar el cumplimiento del tercero, ya que la actividad del deudor y del acreedor en conjunto resulta de por sí suficiente para excluir, en todos los casos, la intervención del tercero, lógica que se encuentra tutelada en nuestro ordenamiento según se ha visto.

El derecho a la liberación del deudor, extraíble de las normas referidas al pago por consignación, se encontraría limitado, en el caso de oposición al cumplimiento del tercero, a que se haya previsto anticipadamente o posteriormente tal posibilidad (ya que el acreedor puede plegarse a dicha oposición), pues ello resulta excepcional frente a la regla anotada a lo largo del presente ensayo referida a la legitimidad genérica y absoluta para que cualquiera pueda cumplir una obligación ajena.

La cláusula general que reconoce a la buena fe como regla del comportamiento de las partes negociales (art. 1362 del Código Civil) claramente impone, sin perjuicio de lo expuesto, que el acreedor, ante el ofrecimiento del tercero, informe inmediatamente al deudor sobre dicha circunstancia a efectos de que pueda ejercitar su derecho a oponerse. Ante la inobservancia de tal deber claro es que no se podrá negar eficacia a la actividad solutoria del tercero, pero dicha omisión generará el consecuente derecho a la indemnización correspondiente a favor del deudor. 